\title{
Our Experience in Database Entry in Ear Surgery Shrestha BL
}

Department of ENT-HNS

Dhulikhel Hospital, Kathmandu University Hospital

Dhulikhel, Kavre, Nepal.

\section{Corresponding Author}

Bikash Lal Shrestha

Department of ENT-HNS

Dhulikhel Hospital, Kathmandu University Hospital

Dhulikhel, Kavre, Nepal.

E-mail: bikashotology@kusms.edu.np

Citation

Shrestha BL. Our Experience in Database Entry in Ear Surgery. Kathmandu Univ Med J. 2020;69(1):84-5.

\begin{abstract}
Otological database is must for every otological surgeon. The surgeons who do not have their own surgical database have difficult in convincing the patients about the outcome of procedure. Looking at the literature review about the concerned surgery does not reflect the success rate of the surgeon who is performing the surgery. So it is very important for every surgeon to have their own data base. The database helps surgeon to improve their skills and compare their own surgical results within and with other literatures. This helps the surgeon to convince patients regarding success and failure rates of their surgery. Not only that, but it also helps to perform prospective research work.
\end{abstract}

\section{KEY WORDS}

Otologic database, Patients, Surgeons

\section{INTRODUCTION}

There should be discussion with patient and visitors before performing any procedure. After proper and good counseling the surgeon and the patient has to sign the informed consent. The discussion before any procedure should be based on the success and failure rates of the procedures. If the surgeons do not have their own surgical database then it is difficult to convince the patients about the outcome of procedure. Though, there are many reports in the literature on the outcome of ear surgery but it is difficult to make comparisons from these reports because of a lack of uniformity. At the same time, the patients and their visitors expects doctors to provide them with information regarding the benefits and risks of surgery, and it is more important in the developing countries like ours where there is high incidence of violence against doctors.

Many ear surgeons will not be able to provide this information because only few have an up-to-date database. So they have to rely on the literature review of other surgeons about their success and failures. In developing country like ours, there is unequal distribution of health insurance, and also the sparse distribution of tertiary health care service, many patients do not come for follow up visit and whoever comes for follow up, do not get postoperative audiogram. Due to high volume of patients in out patient department, many postoperative patients go unnoticed.

Patients with a good hearing result and successful graft uptake may not come for follow up and patients who were not happy with the surgery may not come back for follow up. Hence, before performing any hearing related ear surgeries it is mandatory for any surgeons to look at their success rate. Looking at the literature review about the concerned surgery does not reflect the success rate of the surgeon who is performing the surgery. So it is very important for every surgeon to have their own data base. 


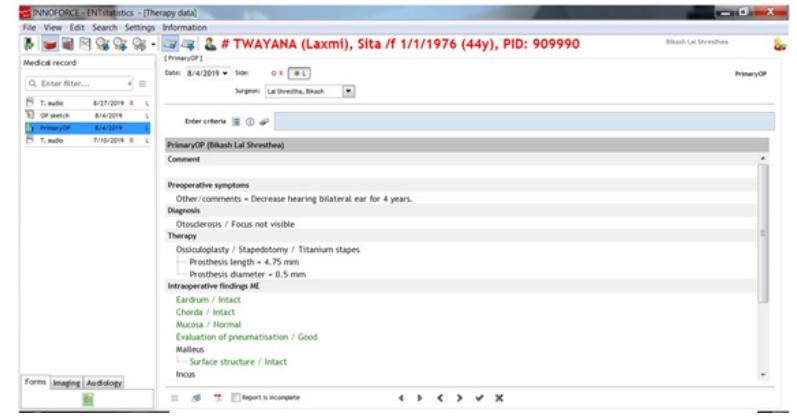

Figure 1. Showing otology database.

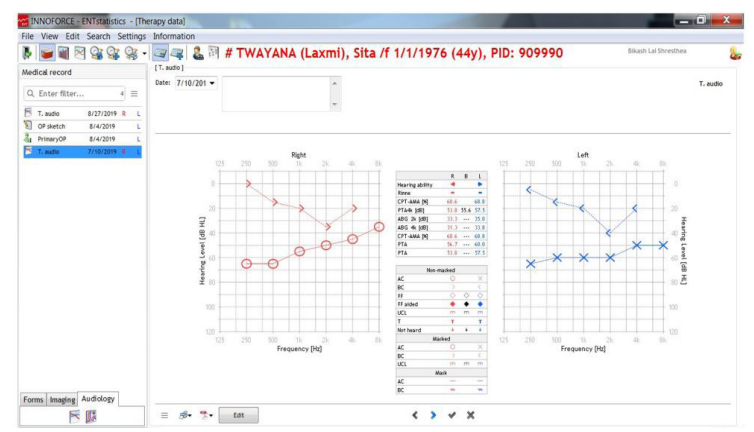

Figure 2. Showing pure tone audiogram.

Most of the institutions in Nepal, the postgraduate students collect audiological and surgical data retrospectively. In those cases, the record is not complete (many a times the audiological results are difficult to get properly) and patients are not willing to participate in an academic investigation. Once the resident has left the department, the results also go along with them. So, in such cases only a prospective electronic database plays important role to set a personal benchmark of the concerned surgeons and helps to compare their results with the literature.

\section{How we maintain the database?}

M. Yung, a promoter of an international common otology database stated in his recent article: "Maintaining an up-to-date otology database demands hard work and dedication from the surgeon". ${ }^{1}$ R. Vincent, another promoter of an otology-neurotology database concludes that only a computerized medical record allows for efficient data storage, easy retrieval, and all options for reviewing data in multiple formats. ${ }^{2}$ Prof. Thomas Linder, states that it is very important to keep all your records as the prospective otologic database because it helps to critically appraise yourself about your surgical results. ${ }^{3}$

We are currently using the ENT Statistics software by Innoforce for entering all the otologic results since 3 years. Till now we have entered 202 cases in the database.

\section{REFERENCES}

1. Yung $M$, Heyning P. A Prospective Multicentre Otology Database. Arnold W, Häusler R (eds): Otosclerosis and Stapes Surgery. Adv Otorhinolaryngol. Basel, Karger, 2007;65: 335-39.

2. Vincent $R$, Sperling $N$, Oates J, Jindal M. Surgical Findings and Long-Term Hearing Results in 3,050 Stapedotomies for Primary Otosclerosis: A Prospective Study with the Otology-Neurotology Database: Otol Neurotol. 2006; 27: 25-47.

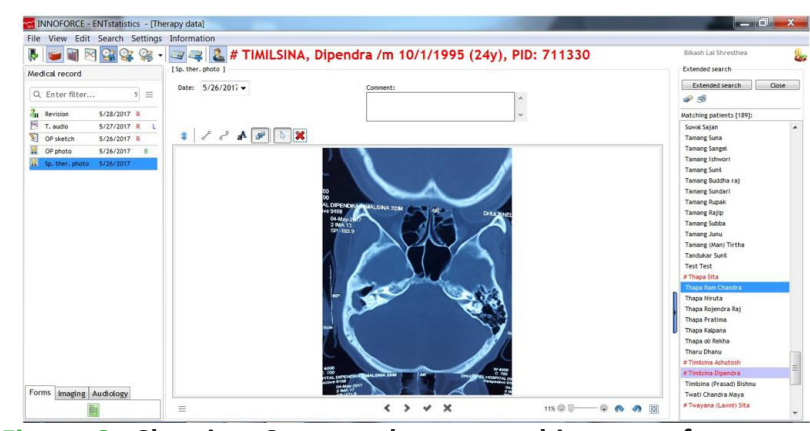

Figure 3. Showing Computed tomographic scan of temporal bone entry in database.

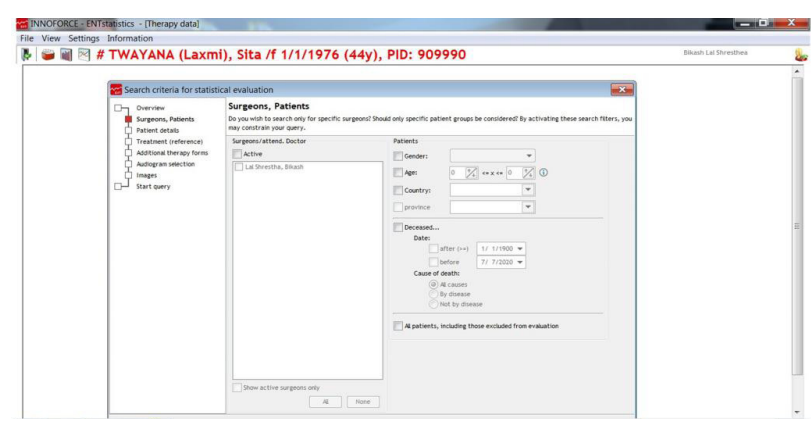

Figure 4. Showing search criteria in software.

In this system, we can automatically import the patient's data, the audiograms, and different intraoperative otological notes (fig. 1, 2). The intraoperative digital photographs and the surgeon's operative drawing can also be scanned at the workstation in the operation theatre. Additionally preoperative CT scans and a PDF file containing operation notes can be inserted (fig. 3). Within 10 minutes the patient's records can prospectively entered into the database. During postoperative visits, the patient's file is retrieved from the database and the follow-up information is easily entered. The surgical data stored in the database can be analyzed meticulously using multiple criteria, and pre and postoperative audiograms can be compared (fig. 4). The results can also be analyzed with statistical analysis within the software and can depict in graphs. So this database is helpful is performing research in different otological surgeries.

\section{CONCLUSION}

Otological database is must for every otological surgeon who wants to improve their skills and compare their own surgical results and also with other literatures. This helps the surgeon to convince patients regarding success and failure rates of their surgery. Not only that, but it also helps to perform prospective research work.

3. Linder TE. The necessity for a prospective, continuous and long term follow-up in otological surgery. http://www.innoforce.info/public docs/press/EN/0901_ENTnews.pdf 